\title{
SOME NEW DIPTERA WITH REMARKS ON \\ THE AFFINITIES OF THE GENUS PNYXIA JOH.
}

\author{
BY F. R. SHAW \\ University of Massachusetts
}

In a lot of material sent to me for identification by Dr. Peter Bellinger, while a student at Yale University, I found some specimens of unusual interest. Most of the insects fall in the genus Bradysia* of the family Sciaridae. There were a few Mycetophilidae.

By far the most interesting insects were small Diptera resembling Cecidomyiidae. The females are wingless and lack halteres. The males have antennae similar to certain gall midges. At first, the specimens were believed to fall in the genus Peyerimhoffia but further study indicated that their affinities were not with this group. It was finally determined that the insects would fall within the genera Pnyxia Johannsen or Epidapus Haliday.

Through the kindness of Alan Stone of the U.S. National Museum, I was able to borrow specimens originally described by Hopkins as Epidapus scabiei but subsequently placed in the genus Pnyxia by Johannsen. Two characters used to recognize Pnyxia include the absence of the dorsal eye-bridge and the shape of the palpi. Since the dorsal eyebridge is greatly reduced in the females I was examining, I wondered if Hopkins could have overlooked this structure. My material also possesses a one-segmented maxillary palpus as is characteristic of Pnyxia.

A thorough study of Pnyxia scabiei (Hopkins) revealed the complete absence of an eye-bridge. The palpi although one-segmented are more or less cup-shaped and possess a great number of small peg-like setae on the concave surface. These are entirely lacking in the specimens I was examining. Another feature I found of value to distinguish my material

* I am following the interpretation of Frey, 1948, of the generic concepts of the Sciaridae. 
from Pnyxia is that in Pnyxia there is a snout-like projection above the antennae.

In general appearance, the males of my specimens closely resemble those of Pnyxia except for the palpal structure and presence of an eye-bridge. The eye-bridge in both sexes is greatly reduced being not over one facet wide in the male and possessing a total of eight facets in the female. In the female most of the facets are located in front of the ocelli and they are easily overlooked.

The systematic position of Pnyxia has been somewhat uncertain. Johannsen, 1912, indicated that according to Enderlein, this genus would be placed in the Mycetophilinae. Edwards, 1925, placed the genus in the Sciophilinae. Frey, 1942, makes the following statement concerning this genus, "nicht zu den Sciariden gehören die Gattungen Pnyxia Joh. und Allostooma Schmitz." My conclusions concerning this matter are that Pnyxia is a sciarid. The thoracic sclerites show that the affinities of the genus are closest to the Sciaridae. The reduced eye-bridge in the specimens I am naming as a new species of Epidapus is certainly a step toward the loss of the eye-bridge in Pnyxia.

A total of four new species was found in the course of study of the specimens. These include Epidapus johannseni, Zelmira williami, Bradysia bellingeri and B. farri. Their descriptions appear herewith.

\section{Epidapus johannseni n. sp.}

Male. Length $1 \mathrm{~mm}$., General color dark brown, legs and abdomen lighter. Resembles a cecidomyiid in general appearance.

Head. Antennae about 1.5 the length of the body. The basal two segments compact, the second bulb-like. The flagellar segments, with the exception of the terminal one, attenuated at the tip, see figure 1. Antennal hairs more or less verticillate. The intermediate antennal segments are about 0.16 as broad as long. The attenuated portion of each of the segments is about 0.33 the length of the entire segment. Compound eyes sparsely hairy. Eye-bridge present, narrow, for the most part possessing a single row of facets. 
Ocelli 3, prominent. Maxillary palpi one-segmented, somewhat paler than rest of mouthparts.

Thorax dark brown. Wing slightly more than $1 \mathrm{~mm}$. long, slender, anal angle greatly reduced. Anterior wing veins most evident. Costa extends about 0.5 the distance from $\mathrm{Rs}$ to $\mathrm{M}_{1+2}$. Humeral crossvein present. Only the radius with macrosetae. $R_{1+2}$ ends at about 0.375 of length of wing. $R_{\mathrm{S}}$ ends before tip of $\mathrm{M}_{3}$ at about 0.78 the length of the wing. Petiole of $\mathrm{M}$ indistinct. Petiole of $\mathrm{Cu}$ is practically absent. In some specimens the anterior branch of $\mathrm{Cu}$ appears to originate from the petiole of M. Halteres pale brown, about 0.25 the length of the wing. Legs dark brown. Tibial spurs present, paired on meso- and metathoracic legs. Anterior tibia about 0.81 the length of the tarsus. The basitarsus is about 0.40 the length of the tibia. Tarsal claws simple. Pulvilli and empodium with prominent hairs.

Abdomen. Brown in color, somewhat paler at tip. Clasper, figure 2, about 0.66 as broad as long has about 6 spines on the mesal, apical surface of which the dorsal one is most conspicuous. Frey's key, 1948, would place this species near E. abieticola Frey described from N. Esbo. It differs in the details of the structure of the hypopygium.

Described from 7 males from Mt. Higby Reservoir, Hartford County, Connecticut, March-July 1951.

Female. Length 1.5-2 mm. General color brown.

Head. Dark brown. Antennae 16-segmented, segments not attenuated at tip as in males. Antennal hairs somewhat verticillate. Antenna about 0.28 the length of the body. Compound eyes sparsely hairy. The number of facets is reduced. Dorsal bridge present but the number of facets not over 8 mainly located in area of bridge anterior to ocelli. Ocelli 3, prominent. Mouthparts small, maxillary palpi one-segmented with two prominent setae.

Thorax. Wings and halteres absent. Legs pale brown.

\section{Explanation of Plate 3}

Fig. 1. Fifth flagellar segment of male Epidapus johannseni. Fig. 2. Dorsal view of male hypopygium of Epidapus johannseni. Fig. 3. Ventral view of male hypopygium of Zelmira williami. Fig. 4. Ventral view of male hypopygium of Bradysia bellingeri. Fig. 5. Ventral view of male hypopygium of Bradysia farri. 


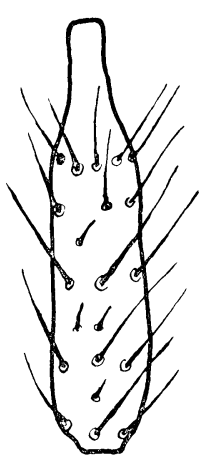

$F|G$.

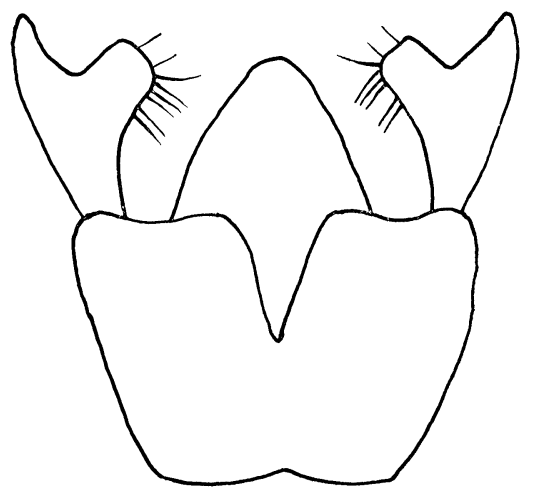

F IG. 3

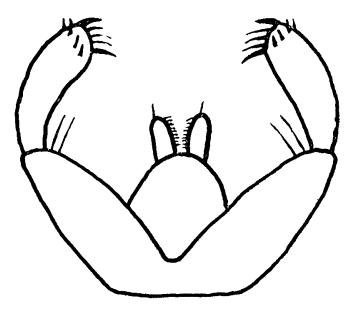

FIG. 4

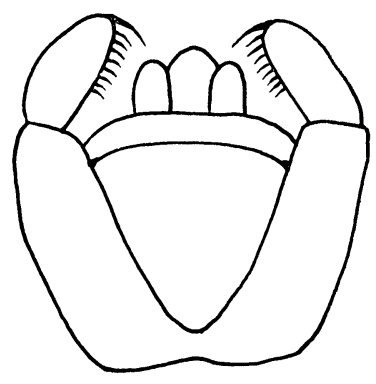

FIG. 5 
Coxae elongate, not especially robust as in Pnyxia scabiei. Tibial spurs present. Prothoracic tibia slightly shorter than tarsus. Basitarsus about 0.33 length of the tibia.

Abdomen pale brown. Ovipositor prominent.

Described from 35 specimens from Mt. Higby Reservoir, Hartford County; Middlefield; and Cathedral Pines, Litchfield County, Connecticut, January-August 1951. Male and female holotypes and 2 paratypes in my collection, the remainder in collection at Yale University.

I take pleasure in naming this species for Dr. O. A. Johannsen, an outstanding American dipterist.

\section{Zelmira williami n. sp.}

Male. Length $6 \mathrm{~mm}$. General color brown.

Head. Dark brown. Antennae short, about subequal to length of the thorax. Ocelli 3. prominent. Maxillary palpi 3-segmented, first segment darker than the other segments.

Thorax. Dark brown. Postnotum with bristles. Pleurites are bare. Wings yellowish with a terminal dark band. Costa terminates at tip of $R_{4+5}$. $S_{1}$ ends before origin of $R s$. $\mathrm{Sc}_{2}$ present, about $1 / 2$ way between humeral crossvein and tip of $\mathrm{Sc}_{1} \cdot \mathrm{R}_{3}$ almost perpendicular to $\mathrm{R}_{4+5}$, ends about 0.33 the distance from tip of $R_{1+2}$ to tip of $R_{4+5}$. A brown band covers the terminal sixth of the wing. Fused portion of $\mathrm{M}$ subequal to the petiole of M. Two distinct anal veins. Legs yellow. The tarsi appear darker due to the presence of numerous black setulae. Prothoracic basitarsus about 0.9 the length of the tibia. Tibial spurs brown. Some of setae on meso- and metathoracic tibiae are arranged in lines. Halteres brown, the knobs a little darker.

Abdomen dark brown. Apices of segments 2-4 with yellow bands. Remainder of segments including the hypopygium dark brown. Clasper, figure 3, of the "genualis" type but lacks the long mesal spur. In Fisher's manuscript key this species would run to Zelmira genualis Joh. It can be distinguished from this species by the shape of the claspers and the shape of the tergum.

Described from 1 male collected in a soil sample from a virgin White Pine and Hemlock stand in Cathedral Pines, 
Litchfield County, Connecticut on May 16, 1951. Type in my collection.

I take pleasure in naming this insect for my son, William Morse Shaw.

\section{Bradysia farri n. sp.}

Male. Length $3 \mathrm{~mm}$. General color dark brown.

Head dark brown. Antennae 16-segmented somewhat paler in color. Mouthparts yellowish brown. Maxillary palpi 3-segmented.

Thorax. Dark brown. Wings $2.75 \mathrm{~mm}$. long. Costa strong, extends about 0.75 distance from tip of $R_{4+5}$ to $\mathrm{M}_{1+2} . \mathrm{R}_{1+2}$ ends at about 0.56 distance from wing base to its tip about opposite fork of M. Rs originates proximad of mid-point between humeral crossvein and tip of $R_{1+2}$. Both branches of radius have setae. $\mathrm{M}_{3}$ ends only slightly beyond tip of $R_{1+2}$. Petiole of cubitus about 0.88 as long as basal portion of media Halteres pale brown. LegsCoxae yellowish brown, remainder of legs yellowish. Ratio of prothoracic basitarsus to its tibia 0.60. Tibial spurs yellowish with dark setulae.

Abdomen dark brown. Hypopygium, figure 5, resembles somewhat that of B. acuta Joh. Clasper with a strong terminal spine and about 8 setae on its inner surface.

In Pettey's key, 1918, this species would run to Bradysia varians Joh. It differs from this species in venation, in the structure of the clasper, and in other details. Described from 1 male collected at Mt. Higby Reservoir, Hartford County, Connecticut on March 7, 1951. Type in my collection.

I take pleasure in naming this insect for Thomas Farr, an outstanding student in entomology who has a firm belief in the value of the study of insects in their natural habitats.

\section{Bradysia bellingeri $n$. sp.}

Male. Length $2.25 \mathrm{~mm}$. General color dark brown.

Head dark brown. Antennae and mouthparts paler. Maxillary palpi 3-segmented, yellowish brown.

Thorax dark brown. Wing $2.0 \mathrm{~mm}$. long. Costa extends 
about 0.75 the distance from tip of $R_{4+5}$ to $M_{1+2}$. $R_{1+2}$ ends proximad of fork $\mathrm{M}$ at about 0.5 the length of the wing. $\mathrm{R}_{\mathrm{S}}$ originates about 0.70 the distance from the humeral crossvein to the tip of $R_{1+2}$. Only the radius has setae. $M_{3}$ ends opposite tip of $R_{4+5}$. Petiole of cubitus about 0.60 as long as basal portion of media. Halteres pale brown, tips darker. Legs yellow, appearing darker toward apices due to presence of fine black setulae. Prothoracic basitarsus about 0.62 as long as the tibia. Tibial spurs yellow.

Abdomen dark brown, terminal portion somewhat paler. Hypopygium, figure 4, resembles Bradysia diluta Joh. somewhat.

In Pettey's key, 1918, this species would run to Bradysia scita Joh. It can be distinguished from B. scita by the structure of the clasper of the hypopygium which lacks a mesal lobe as shown for scita. In addition $B$. bellingeri possesses a strong apical spine and 3 sub-apical spines on the mesal surface. Described from 1 male collected in a soil sample from a stand of Red Pine at Mt. Higby Reservoir, Hartford County, Connecticut on March 27, 1951. Type in my collection.

I take pleasure in naming this species for Dr. Peter Bellinger who sent me these specimens for determination.

EDWARDS, F. W.

REFERENCES

1925. British Fungus-Gnats. Trans. Ent. Soc. London, 1924: 505-670, pls. $49-61$.

Frey, R.

1942. Entwurf einer neuen Klassifikation der Mückenfamilie Sciaridae. Not. Ent., 22:5-44, figs. 1-12.

1948. Entwurf einer neuen Klassifikation der Mückenfamilie. Sciaridae. II Die nordeuropäischen Arten. Not. Ent., 27:33-92, figs. 1-136.

JOHANNSEN, O.A.

1912. The Fungus Gnats of North America. Maine Agric. Exp. Sta. Bull., 200:57-146, figs. 24-267. 

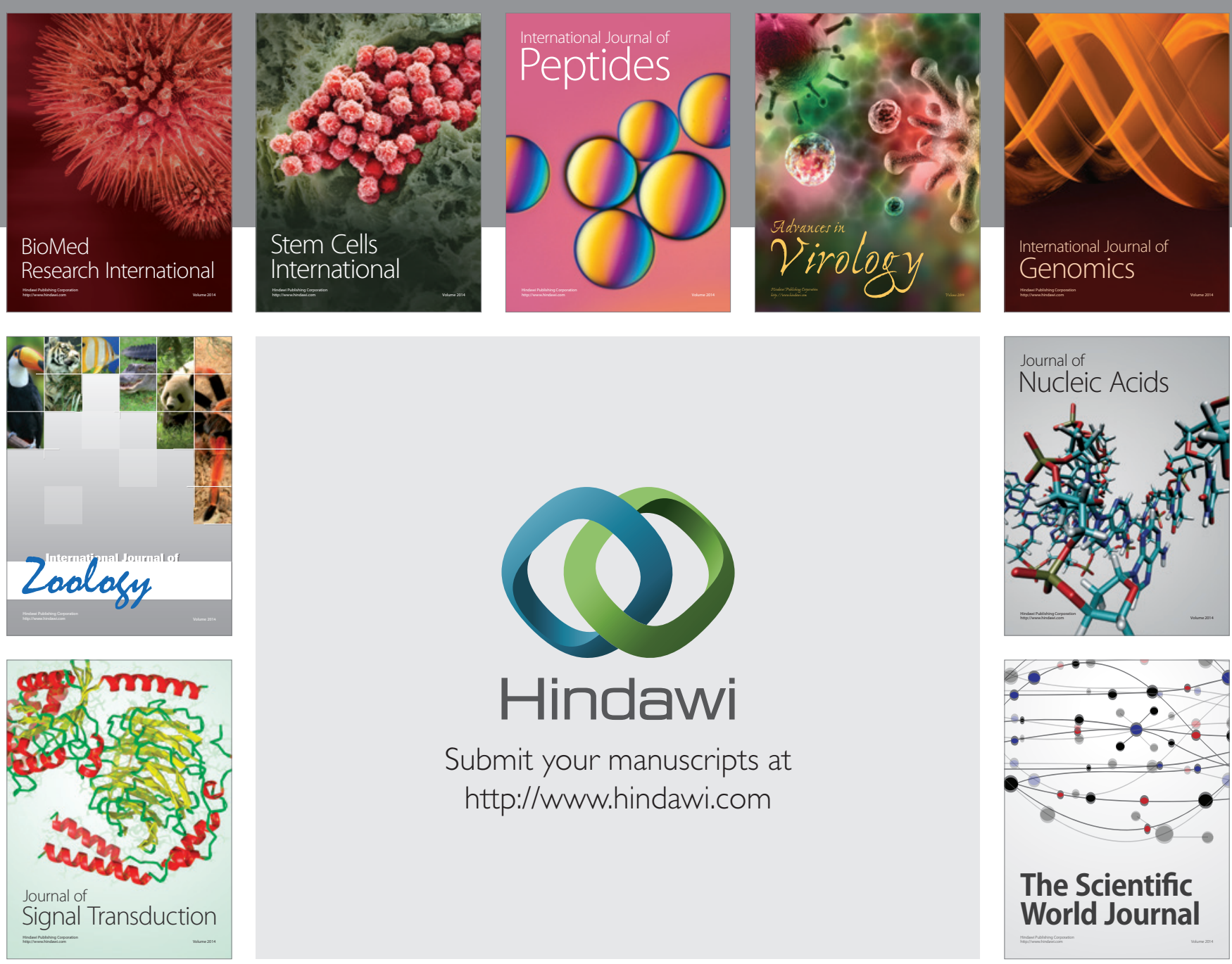

Submit your manuscripts at

http://www.hindawi.com
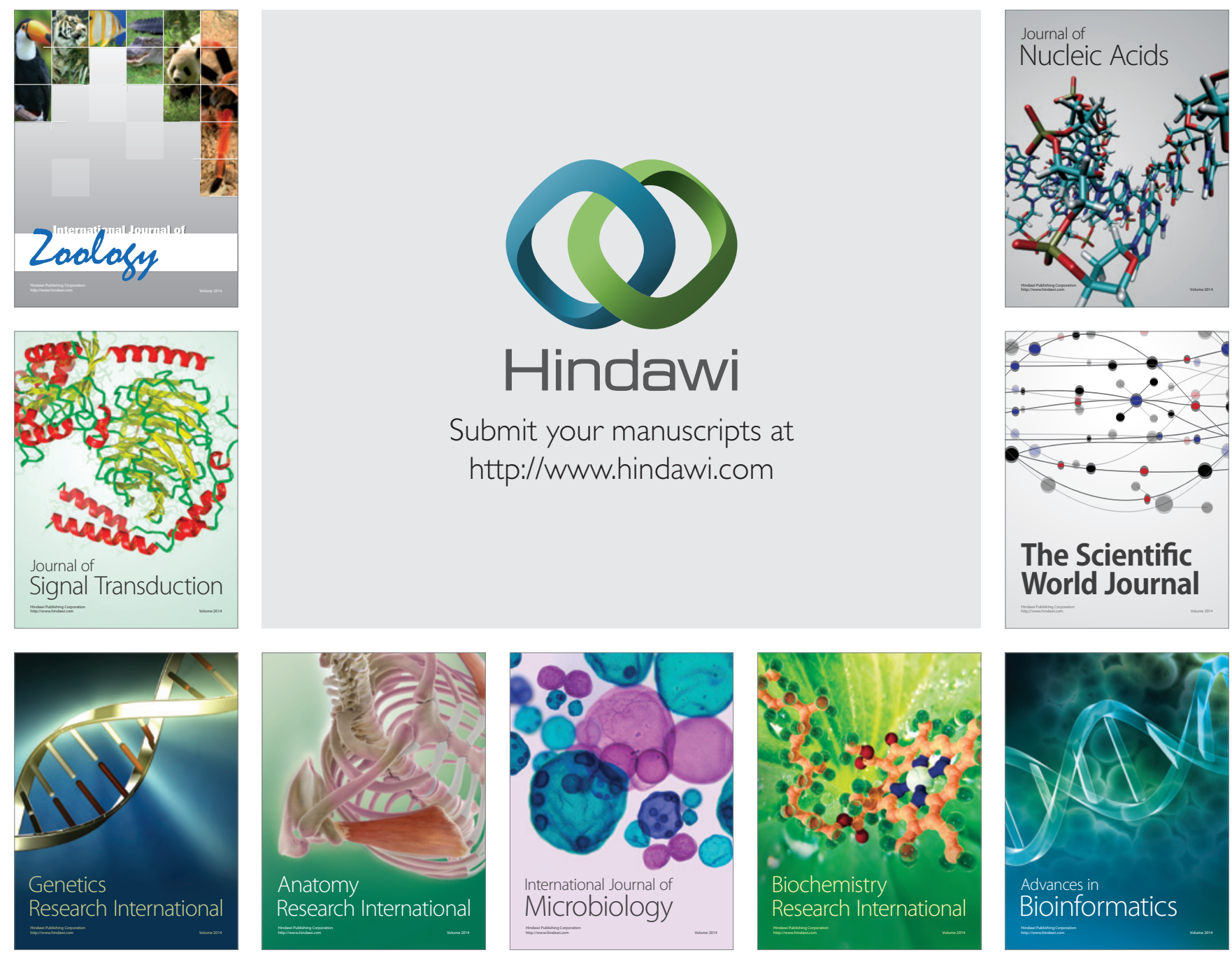

The Scientific World Journal
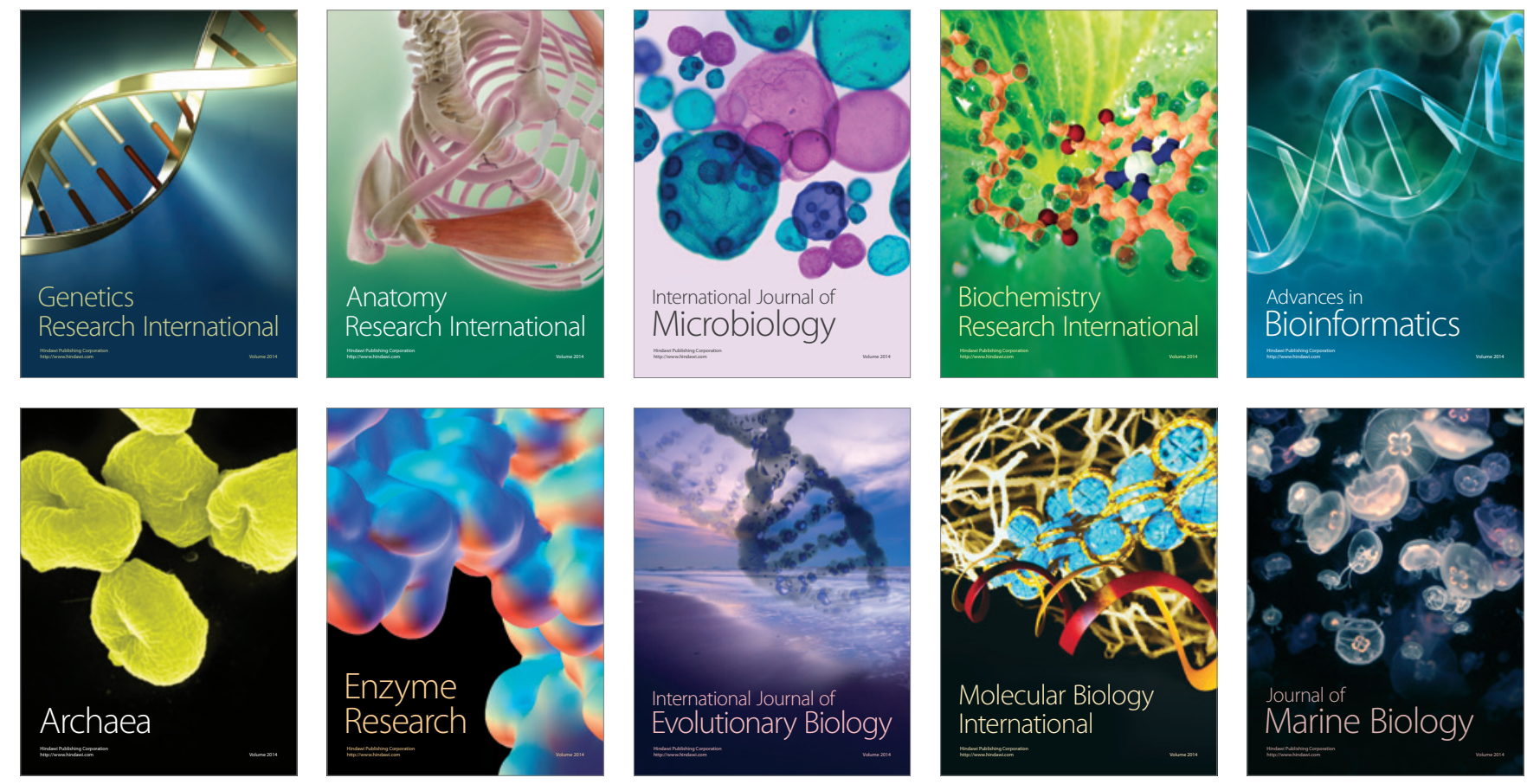